\title{
Optimization Strategy of Internal Value Chain of Coal Preparation Plant Based on Cost Control
}

\author{
Jingwen An \\ China University of Mining and Technology (Beijing) \\ Management School of CUMTB \\ Beijing, China, 100083 \\ ajw1200@263.net
}

\author{
Xiuling Zhang \\ China University of Mining and Technology (Beijing) \\ Management School of CUMTB \\ Beijing, China, 100083 \\ zxlflying.2013@yahoo.com
}

\begin{abstract}
Coal-separating is the most important procedure in the coal industry with the highest value-added rate.It will have vital significance to the coal industry tooptimize coal preparation plant's value chain, control its cost and improve its efficiency.Based on this,this article first establishes the coal preparation plant's internal value chain model using the quantitative analysis method;Then the author deduces comprehensive weights of each index in the model by the analytic hierarchy process (ahp);Nextthe article establishes a dynamic evaluation mathematical model of coal preparation plant's e internal value chain combining with fuzzy linear programming and the time factor;At last the optimization model of coal preparation plant's e internal value chain is calculated,which provide a quantitative and dynamic cost control strategy for coal preparation plant. Research shows that the quantitative analysis of enterprise internal value chain, provides managers with a quantitative analysis of the enterprise cost control from the perspective of value chain of the basis, and scientifically builds a fuzzy linear programming model, and achieves the overall interests of the value chain optimization.
\end{abstract}

Keywords-Cost control; value chain; analytic hierarchy process(ahp); fuzzy linear programming

\section{INTRODUCTION}

From the time China has been established, the main method to manage the coal industries in China is extensive management, especially in the aspect of cost control where the plan has been made by experiencefor the most time and therefore is short of scientific reliance as well as quantitative analysis. Also the plan rarely combines with the key procedure in the enterprise to proceed management control. In recent years, enterprise's value chain administration has always been one of the hotter topics in and out of China because the study in optimizing value chain satisfies the need of the managing development and embodies the managing goal of increasing the value $^{[1]}$.Quantitative analysis of value chain in the application of the enterprise strategy cost control plays a key role in raising the ability of core competitiveness and benefit of the enterprise. The researchers out of China include Michael E.Porter(1985), Shank(1995), Govindarajan(1995), Slywotzky(2002) and so on ${ }^{[2]}$. The concept of value chain was first presented by Michael E.Porter and he thought that the competitiveness among companies was existed in not only certain procedure but the whole processes ${ }^{[3]}$. Shank and other researchers make a further study in the value chain theory and in the basis of Porter' theory, they proposed that the management in value chain is equal to the system procedure of optimizing the enterprise's value chain[1]. There are also abundantresearch results concerning the theory and practice of value chain in China. However most of the researches focus on service industry, financial industry and commerce industry. Such as Jingkui Shao discusses the new development of modern tourism industry value chain model and its optimization mechanism[2],ShuliFeng analyses the formation mechanism of commercial Banks competitiveness from the perspective of value chain ${ }^{[4]}$, YueHuang uses manufacturing industry for an example to studyenterprise internal value chain optimization model with the method of quantitative analysis ${ }^{[5]}$.The study of value chain in the coal industry is relatively little, and the method is single. While in the whole industrial chain of the coal industry, coal washing and processing is a significant procedure in increasing the value of the coall ${ }^{[6]}$. It is really significant to the whole coal procedure to integrate the internal value chain of coal preparation plant, control the cost scientifically and enhance the enterprise's operating efficiency.

Based on what is mentioned, this article in time applies the concept of optimizing the value chain which is based on cost control to coal preparation plants. In this research, we use the quantitative analysis method which is a combination of AHP and FLP. This method will also be combined with time factor to proceed an optimal analysis of the coal preparation internal value chain. We hope that the method could supply the management concept of the coal industry and offer scientific reliance for the cost control in the coal company.

\section{CONSTRUCT VALUE CHAIN STRUCTURE OF COAL PREPARATION PLANT}

The concept of value chain is proposed by Michael E.Porter in Harvard Business School in 1985. Porter pointed out that "Enterprise's value creation is constituted by a series of activities, and these activities can be divided into two categories, basic activities and auxiliary activities, among them, basic activities are including internal logistics, production operation, external logistics, marketing, sales and service, etc.; And auxiliary activities are including 
procurement, technology development, human resource management and enterprise infrastructure, etc. These different from each other but interrelated production and business activities, constitute a dynamic process of creating value, that is value chain" ${ }^{[4]}$.In fact, in order to have a profound understanding and an exact optimal analysis to the value chain, the relationship among each procedure in the value chain should be hold.

From the value chain point view, it needs to consume resources to proceed each value activity and at the same time to form products. The purpose for the enterprises to be engaged in the value activity is to offer products to the clients as well as obtaining profits which are beyond the consumed resources $^{[1]}$. Such benefits which the clients are willing to pay for the companies are called customer value. That is to say, in order to achieve more profits, the enterprises must create more customer value and lower the resources and the costs. From certain degree, the value of an enterprise is reflected in the client value. Therefore the author thinks that the target of value chain optimizing is to maximize the customer value. Simultaneously, constraints should be added to the costs of the products which are produced by enterprises. In this article, we will introduce dynamic and marginal cost to determine the optimal costs in Tth year within one strategic planning period(generally 5 years). To specify it, we take XSMD Taiyuan coal preparation plant in as an example and show the value chain structure in Fig. 1.

As shown in Fig. 1, AHP is first used to get weights of each value activity within coal preparation value chain based on customer value. Then in the result analysis, cost allocation value of each value activity in Tth year within one strategic planning period is calculated by collecting cost allocation value of every value activity in recent two years (2011 and 2012) and FLP method. At last, according to the amount and proportion of costs in each value activity, we will define the value chain structure after optimizing.

\section{FLP OF ENTERPRISES' VALUE CHAIN OPTIMIZATION}

Strong fuzziness is the characteristic of business operation and decision activity especially every value activity in enterprise value chain. Also, as the costs occurred during the enterprise production are influenced by dynamic factors such as time factor and market uncertainty factor, cost constraint is not fixed. So FLP is a better method to solve these problems.

FLP is a method that fuzzy the constraint condition (dynamic and marginal cost) and target function (customer value) and introduce subordinate functions to obtain a new LP. Through solving the new LP, the optimal solution (customer value maximization) is achieved.

\section{A. General Formation of FLP}

$$
\begin{aligned}
& \max f(x)=c_{1} x_{1}+c_{2} x_{2}+\cdots+c_{n} x_{n} \\
& \text { s.t. }\left\{\begin{array}{l}
a_{11} x_{1}+a_{12} x_{2}+\cdots+a_{1 n} x_{n} \leq b_{1} \\
a_{21} x_{1}+a_{22} x_{2}+\cdots+a_{2 n} x_{n} \leq b_{2} \\
\cdots \cdots \\
a_{m 1} x_{1}+a_{m 2} x_{2}+\cdots+a_{m n} x_{n} \leq b_{m} \\
x_{1}, x_{2}, \cdots, x_{n} \geq 0
\end{array}\right.
\end{aligned}
$$

The general model of the FLP is

Where " $\leq$ " represents "less than or equal toapproximately".

Assume that $F=\left\{X \mid X=\left(x_{1}, x_{2}, \cdots, x_{n}\right)^{T}\right\} \quad$ is an $\mathrm{n}$

$$
D_{i}(X)=\left\{\begin{array}{l}
1, \sum_{j=1}^{n} a_{i j} x_{j} \leq b_{i} \\
1-\frac{1}{d_{i}}\left(\sum_{j=1}^{n} a_{i j} x_{j}-b_{i}\right), b_{i}<\sum_{j=1}^{n} a_{i j} x_{j} \leq b_{i}+d_{i} \\
0, \sum_{j=1}^{n} a_{i j} x_{j}>b_{i}+d_{i}
\end{array}\right.
$$

dimension vectorand $X \geq 0$. We substitute $m$ elastic restraints in (1) for m fuzzy sets $D_{i}(i=1,2, \cdots, m)$ on filed $\mathrm{F}$, its subordinate function is

Where $d_{i}(i=1,2, \cdots, m)^{T}$ are the given nonnegative constants, and are called flexible indicators, denoted $d=(i=1,2, \cdots, m)^{T}$. Let $\mathrm{D}=\mathrm{D}_{1} \cap \mathrm{D}_{2} \cap \cdots \cap \mathrm{D}_{\mathrm{m}} \quad$ construct fuzzy constraint set.

In order to find the optimal fuzzy solution of (1), the target function is changed to a fuzzy inequality $f(X) \geq f_{0}$, where $f_{0}$ is a normal LP optimal value:

$$
\begin{aligned}
& G(X)=\left\{\begin{array}{l}
0, \sum_{j=1}^{n} c_{j} x_{j}<f_{0} \\
\frac{1}{d_{0}}\left(\sum_{j=1}^{n} c_{j} x_{j}-f_{0}\right), f_{0} \leq \sum_{j=1}^{n} c_{j} x_{j}<f_{0}+c \\
1, f_{0}+d_{0} \leq \sum_{j=1}^{n} c_{j} x_{j}
\end{array}\right. \\
& f_{0}=\max \{f \mid f=C X, A X \leq b, X \geq 0\} .
\end{aligned}
$$

This fuzzy inequality could be described by fuzzy set $G$ and the subordinate function is defined as

Where $f_{0}+d_{0}=\max \{f \mid f=C X . A X \leq b+d, x \geq 0\}$ $A=\left(a_{i j}\right)_{m \times n}$ is the coefficient matrix of (1). $C=\left(c_{1}, c_{2}, \cdots, c_{n}\right), b=\left(b_{1}, b_{2}, \cdots, b_{m}\right)^{T}, d=\left(d_{1}, d_{2}, \cdots, d_{m}\right)^{T}$.

Let $M=D \cap G$,

We will get the best decision $X^{*}$, to satisfy

$$
M\left(X^{*}\right)=\max _{x \geq 0}(M(X))=\max _{x \geq 0}(D(X) \wedge G(X))
$$


$X^{*}$ here is the optimal solution of FLP (1).

Assume $\lambda=D(X) \wedge G(X)$, (4) could be transferred to the following LP:

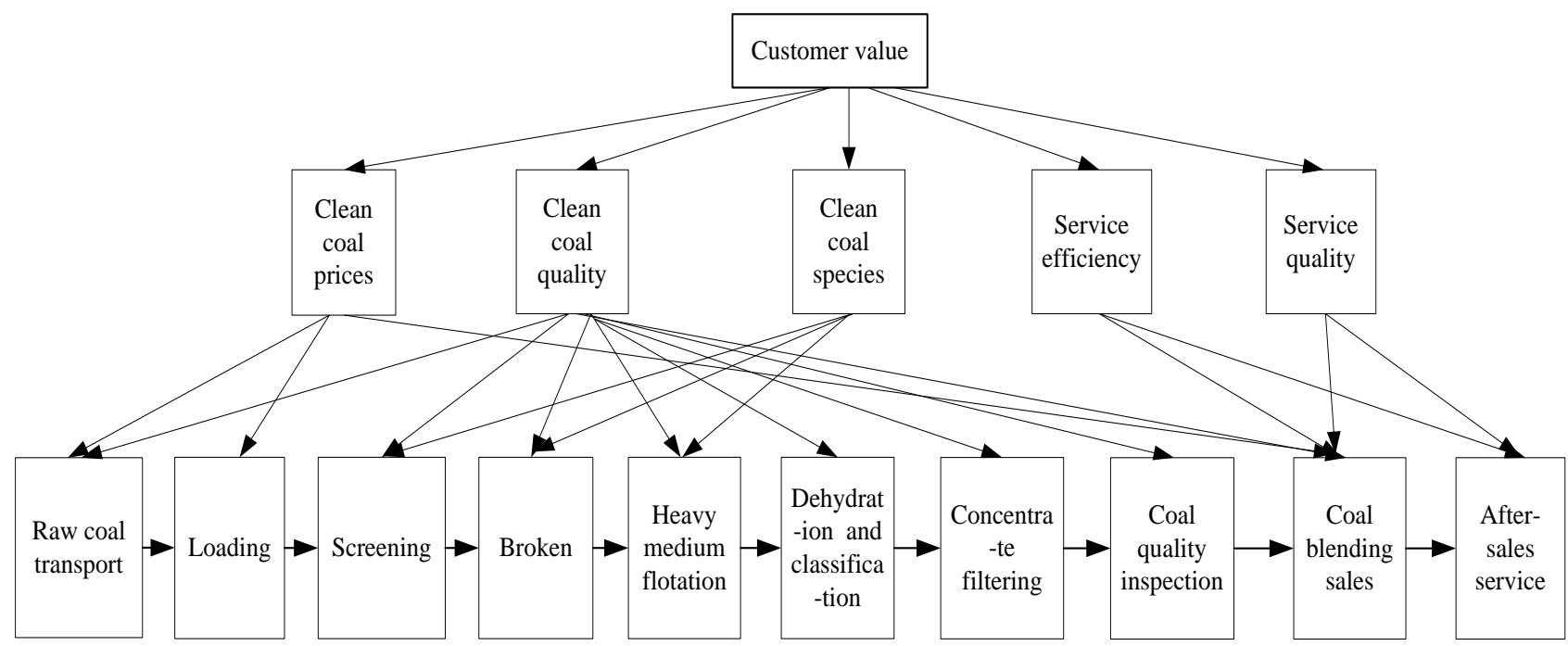

Figure 1. Value chain structure of coal preparation plant based on customer value

$$
\text { s.t. }\left\{\begin{array}{l}
\max \lambda \\
\sum_{j=1}^{n} a_{i j} x_{j}+d_{j} \lambda \leq b_{i}+d_{i}, i=1,2, \cdots, m \\
j=1 \\
0 \leq \lambda \leq 1 \\
x_{1}, x_{2}, \cdots x_{n} \geq 0
\end{array}\right.
$$

To solve (5), $X^{*}=\left(x_{1}^{*}, x_{2}^{*}, \cdots x_{n}^{*}\right)^{T}$ could be attained.

\section{B. Determine Target Function of Value Chain Optimal Model}

At first, according to the ten value activities of coal preparation plant's internal value chain in the third program layer in Fig.1, each value activities' contribution to customer value is determined.

Provided that $a_{i}(\mathrm{i}=1,2, \cdots, 10)$ are weight coefficients of customer value, we will determine the value of $a_{i}$ by AHP method.

Let decision variable be the cost allocation values $x_{i}^{T}$ (i=1,2, $\cdots, 10)$ of ten value activities (as in Fig.1) from raw coal transportation to the whole procedure of washing coal in after-sale service in Tth year. In every planning period $[0$, $\mathrm{T}$ ], the incident indicator of each year is $0<1<\cdots<\mathrm{T}-1<\mathrm{T}$.

The parameters included in the constraint conditions are as follows: the total product cost of the company is TC, the initial total cost of enterprise's strategic planning period is $x_{i}^{0}$, the total cost in first year is $\mathrm{TC}^{1}$, the cost allocation of the value activity is $x_{i}^{1}$, the total cost in Tth year is $\mathrm{TC}^{\mathrm{T}}$.

The customer value conversion coefficient $\omega_{i}^{T}$ is introduced here and it represents the proportion of transferring from cost allocation value of each value activity to customer value, $\omega_{i}^{T}=\omega^{T} \bullet a_{i}$, where $\omega^{T}$, which is evaluated by multilevel fuzzy is the comprehensive value of the effect that customer value has been realized by ten value activities and we limit it that $0 \leq \omega^{T} \leq 1$. So the total customer value created by company's products can be represented by:

$f(X)=\sum_{i=1}^{10} \omega^{T} a_{i} X_{i}^{T}$

The goal function of FLP under value chain optimization is

$\max f(X)=\max \left(\omega^{T} \sum_{i=1}^{10} a_{i} x_{i}^{T}\right)$

\section{Determine the Constraint Function of Value Chain Optimizing Model}

The constraint functions have been shown in the first chapter, which are the dynamic cost constraint and the marginal cost constraint. We will solve the practical problem of cost allocation value of each value activity according to FLP and the relative constraint.

1) Constraint function of total dynamic cost

Combined with the practical of the company, the constraint condition of total cost in Tth year is 


$$
\sum_{i=1}^{10} x_{i}^{T} \leq T C^{T} \quad \text {.8) }
$$

\section{2) Constraint function of marginal cost}

When average cost of total cost analysis is adopted, the increment of long time benefits may be underestimated.

Ifmarginal analysis method is used, we could avoid such problem better ${ }^{[8]}$. In the light of the characteristic of marginal cost, the profit of the company would be optimizing when the marginal cost become the minimum. Assume the production value in the th yearis $Q^{t}$, then the marginal production is $Q^{t}-Q^{t-1}$. Of According to the definition of marginal cost, we know that the total cost, which is noted as $M C^{t}$, of all the value activities of the

$$
M C^{t}=\lim _{Q^{t} \rightarrow Q^{t-1}} \frac{\sum_{i=1}^{10} x_{i}^{t}-\sum_{i=1}^{10} x_{i}^{t-1}}{Q^{t}-Q^{t-1}}
$$

value chain is

To minimize the total cost in Tthyear,should be satisfied.

$$
\begin{gathered}
0 \leq M C^{t} \leq M C^{t-1}, t=1,2, \cdots, T \\
M C^{T}=\min _{0 \leq t \leq T}\left\{M C^{t}\right\}
\end{gathered}
$$

Reuse the formulation of (9) and (10) and aeal wim them fuzzily, constrain function of marginal cost is achieved:

$$
\sum_{i=1}^{10} x_{i}^{T} \leq T \sum_{i=1}^{10} x_{i}^{1}-(T-1) \sum_{i=1}^{10} x_{i}^{0}
$$

3) Constraint function of cost allocation value of every value activity

In this article, the cost allocation value of each value activity in Tth year is predicted by the company based on the current cost allocation value of each value activity. The lower limit of the cost of each value activity could be achieved approximately to allocate the total cost within the allowing range. Considering the approximation of the lower

$$
-x_{i}^{T} \leq-x_{i}^{0}, i=1,2, \cdots, 10
$$

limit, we could obtain the fuzzy constraint of the cost allocation value: is

In conclusion, the FLP model of value chain optimizing

$$
\text { s.t. }\left\{\begin{array}{l}
\sum_{i=1}^{10} x_{i}^{5} \leq 40601 \\
\sum_{i=1}^{10} x_{i}^{5} \leq 40000 \\
-x_{i}^{5} \leq-x_{i}^{0}, i=1,2, \cdots, 10 \\
x_{i}^{5} \geq 0, i=1,2, \cdots, 10
\end{array}\right.
$$

$$
\max f(X)=\max \left(\omega^{T} \sum_{i=1}^{10} a_{i} \bullet x_{i}^{T}\right)
$$
$\sum_{i=1}^{10} x_{i}^{1}$

From the model, we can see that when $\mathrm{T}_{\mathrm{TC}} \mathrm{TC}^{\mathrm{T}} \sum_{i=1}^{10} x_{i}^{0}$, and $d_{j}(j=1,2, \cdots 10)$ are definite, the ratio of the adopted cost allocation value in each value activity to the cost could also be determined. Then sort value activities according to cost proportion and compare it to the current cost structure to obtain the value activity which needs to be improved, and go a step further to achieve the goal of optimizing the value chain.

\section{EMPIRICAL ANALYSIS}

In this part, the established FLP model of value chain optimization as well as the collected data will be utilized to proceed value chain optimization analysis of XSMD Taiyuan coal preparation plant.

\section{A. Determine Weight of Each Value Activity}

XSMD Taiyuan coal preparation plant adopts the united process flow to choose the coal, which relies mainly on heavy medium suspension while elimination process subsidiary. In this article, the author takes the example of analyzing the heavy medium suspension coal preparation process. The major value activities(as in Fig.1) are in turn Raw coal transportation, Loading, Screening, Broken, Heavy medium flotation, Dehydration and classification, Concentrate filtering, Coal quality inspection, Coal blending sales and After-sales service. Next we will use AHP to determine the weights which are contributed by these ten value activities to enterprise's customer value.

AHP is a method that the relative importance between every two indicators is first obtained based on Delphi method. Then a judgment matrix is formed by average processing and we normalization process it to retain each evaluating indicator's influence[9]. The writer respectively constructs customer value judgment matrix, refined coal price judgment matrix, refined coal quality judgment matrix, refined coal classification judgment matrix, service efficiency judgment matrix and service quality judgment matrix in the light of the form of the expert consultation as well as one to nine ratio scale. We will also test the uniformity of each judgment matrix.The uniformity results are shown in TABLE I to TABLEVI.

\section{B. Obtain FLP Model of XSMD Taiyuan Coal Preparation Plant's Value Chain Optimization}

In the article, we stipulate a strategy planning period of XSMD Taiyuan coal preparation plant is 5 years $(\mathrm{T}=5)$ and we assume that $\mathrm{d} 1=600, \mathrm{~d} 2=\mathrm{d} 3=\ldots=\mathrm{d} 12=60$. The cost allocation value of XSMD Taiyuan coal preparation plant's each value activity in 2011 and 2012 is shown in TABLE VII. 
From TABLE VII, we can see that $\sum_{i=1}^{10} x_{i}^{0}=24576$ $\sum_{i=1}^{10} x_{i}^{1}=27781$, the total cost of XSMD Taiyuan coal

$$
\begin{aligned}
& \max f(x)=\max \left(0.13 x_{1}^{5}+0.03 x_{2}^{5}+0.08 x_{3}^{5}+\right. \\
& 0.09 x_{4}^{5}+0.14 x_{5}^{5}+0.03 x_{6}^{5}+0.06 x_{7}^{5}+0.04 x_{8}^{5}+(16) \\
& \left.0.38 x_{9}^{5}+0.02 x_{10}^{5}\right)
\end{aligned}
$$$$
\text { preparation plant's strategy planning period } T C^{5}=40000 \text {, }
$$

then the FLP model of value chain optimization of it is

TABLE I. CLEAN COAL PRICE JUDGMENT MATRIX AND RESULT OF UNIFORMITY TEST

\begin{tabular}{|c|c|c|c|c|c|c|c|}
\hline Customer Value & $\begin{array}{c}\text { Clean } \\
\text { Coal Price }\end{array}$ & $\begin{array}{c}\text { Clean coal } \\
\text { quality }\end{array}$ & $\begin{array}{c}\text { Clean coal } \\
\text { species }\end{array}$ & $\begin{array}{c}\text { Service } \\
\text { efficiency }\end{array}$ & $\begin{array}{l}\text { Service } \\
\text { Quality }\end{array}$ & WI & $\begin{array}{c}\text { Uniformity } \\
\text { Ratio }\end{array}$ \\
\hline Clean Coal Price & 1 & 1 & $1 / 3$ & 5 & 4 & 0.2229 & \multirow{5}{*}{0.0361} \\
\hline Clean Coal Quality & 1 & 1 & 1 & 6 & 5 & 0.3012 & \\
\hline Clean Coal Species & 3 & 1 & 1 & 4 & 6 & 0.3588 & \\
\hline Service Efficiency & $1 / 5$ & $1 / 6$ & $1 / 4$ & 1 & 1 & 0.0586 & \\
\hline Service Quality & $1 / 4$ & $1 / 5$ & $1 / 6$ & 1 & 1 & 0.0586 & \\
\hline
\end{tabular}

\begin{tabular}{|c|l|l|l|l|l|}
\hline CleanCoal Price & $\begin{array}{c}\text { Raw Coal } \\
\text { Transportation }\end{array}$ & \multicolumn{1}{|c|}{ Loading } & \multicolumn{1}{c|}{$\begin{array}{c}\text { Coal Blending } \\
\text { Sales }\end{array}$} & Wniformity Ratio \\
\hline Raw Coal Transportation & 1 & 7 & 1 & 0.4995 & \multirow{2}{*}{0.0336} \\
\hline Loading & $1 / 7$ & 1 & $1 / 4$ & 0.086 & \\
\cline { 1 - 4 } Coal Blending Sales & 1 & 4 & 1 & 0.4145 & \\
\cline { 1 - 3 }
\end{tabular}

TABLE II. CUSTOMER VALUEJUDGMENT MATRIX AND RESULT OF UNIFORMITY TEST

TABLE III. CLEAN COAL QUALITY JUDGMENT MATRIX AND RESULT OF UNIFORMITY TEST

\begin{tabular}{|c|l|l|l|l|l|l|}
\hline Clean Coal Quality & $\begin{array}{c}\text { Heavy } \\
\text { Medium } \\
\text { Flotation }\end{array}$ & $\begin{array}{c}\text { Coal } \\
\text { Blending } \\
\text { Sales }\end{array}$ & Broken & Screening & WI & Uniformity Ratio \\
\hline Heavy Medium Flotation & 1 & $1 / 2$ & 1 & 1 & 0.1815 & \multirow{2}{*}{0.0226} \\
\hline Coal Blending Sales & 2 & 1 & 4 & 4 & 0.5133 & \\
\hline Broken & 1 & $1 / 4$ & 1 & 1 & 0.1526 & \\
\hline Screening & 1 & $1 / 4$ & 1 & 1 & 0.1526 & \\
\hline
\end{tabular}

TABLE IV. SERVICE EFFICIENCY JUDGMENT MATRIX AND RESULT OF UNIFORMITY TEST

\begin{tabular}{|c|l|l|l|l|}
\hline Service Efficiency & CoalBlendingSales & After-sale Service & WI & Uniformity Ratio \\
\hline Coal Blending Sales & 1 & 6 & 0.8571 & 0 \\
\hline After-sale Service & $1 / 6$ & 1 & 0.1429 & \\
\hline
\end{tabular}

TABLE V. SERVICE QUALITY JUDGMENT MATRIX AND RESULT OF UNIFORMITY TEST

\begin{tabular}{|c|l|l|l|l|}
\hline Service Quality & Coal Blending Sales & After-sale Service & WI & Uniformity Ratio \\
\hline Coal Blending Sales & 1 & 6 & 0.8571 & 0 \\
\hline After-sale Service & $1 / 6$ & 1 & 0.1429 & \\
\hline
\end{tabular}

TABLE VI. REFINED COAL QUALITY JUDGMENT MATRIX AND RESULT OF UNIFORMITY TEST

\begin{tabular}{|c|l|l|l|l|l|l|l|l|l|}
\hline $\begin{array}{c}\text { Clean Coal } \\
\text { Quality }\end{array}$ & $\begin{array}{c}\text { Raw Coal } \\
\text { Transpor-t } \\
\text { ation }\end{array}$ & Loading & Screening & Broken & $\begin{array}{c}\text { Heavy } \\
\text { Medium } \\
\text { Flotation }\end{array}$ & $\begin{array}{c}\text { Dehydration } \\
\text { and } \\
\text { Classification }\end{array}$ & $\begin{array}{c}\text { Concent- } \\
\text { rate } \\
\text { Filtering }\end{array}$ & $\begin{array}{c}\text { Coal } \\
\text { Quality } \\
\text { Inspection }\end{array}$ & $\begin{array}{c}\text { WI } \\
\text { Uniform } \\
\text { ity Ratio }\end{array}$ \\
\hline $\begin{array}{c}\text { Raw Coal } \\
\text { Transportatio } \\
\text { n }\end{array}$ & 1 & 3 & 1 & $1 / 3$ & $1 / 5$ & $1 / 2$ & $1 / 4$ & $1 / 2$ & 0.0637 \\
\hline Loading & $1 / 3$ & 1 & 1 & 1 & $1 / 6$ & $1 / 6$ & $1 / 4$ & $1 / 3$ & 0.0473 \\
\hline Screening & 1 & 1 & 1 & 1 & $1 / 3$ & 1 & 0.0943 \\
\hline Broken & 3 & 1 & 1 & 1 & 1 & 1 & $1 / 2$ & 2 & 0.0961 \\
\hline $\begin{array}{c}\text { Heavy } \\
\text { Medium } \\
\text { Flotation }\end{array}$ & 5 & 6 & 3 & 1 & 1 & 1 & 2 & 1 & 0.1264 \\
\hline $\begin{array}{c}\text { Dehydration } \\
\text { and } \\
\text { Classification }\end{array}$ & 2 & 4 & 1 & 1 & 1 & 1 & $1 / 5$ & $1 / 3$ & 0.0888 \\
\hline $\begin{array}{c}\text { Concentrate } \\
\text { Filtering }\end{array}$ & 4 & 4 & 2 & 1 & $1 / 2$ & 5 & 1 & 1 & \\
\hline $\begin{array}{c}\text { Coal Quality } \\
\text { Inspection }\end{array}$ & 2 & 3 & $1 / 2$ & 1 & 1 & 3 & 1 & 1 & 0.1906 \\
\hline
\end{tabular}


TABLE VII. COST ALLOCATION OF EACH VALUE ACTIVITY（UNIT: MILLION YUAN)

\begin{tabular}{|c|c|c|c|c|c|c|c|c|c|}
\hline $\begin{array}{c}\text { Value } \\
\text { Activity }\end{array}$ & $\begin{array}{c}\text { Row Coal } \\
\text { Transpo-rtati } \\
\text { on }\end{array}$ & $\begin{array}{c}\text { Loading } \\
\text { Year }\end{array}$ & Screening & Broken & $\begin{array}{c}\text { Heavy } \\
\text { Medium } \\
\text { Flotation }\end{array}$ & $\begin{array}{c}\text { Dehydrating } \\
\text { and } \\
\text { Classification }\end{array}$ & $\begin{array}{c}\text { Concentrate } \\
\text { Filtering }\end{array}$ & $\begin{array}{c}\text { Coal } \\
\text { Quality } \\
\text { Inspection } \\
\text { Blending } \\
\text { Sales }\end{array}$ & $\begin{array}{c}\text { After- } \\
\text { salesSe } \\
\text { rvice }\end{array}$ \\
\hline $\mathbf{2 0 1 1}$ & 2325 & 4318 & 867 & 525 & 10610 & 759 & 701 & 2350 \\
\hline $\mathbf{2 0 1 2}$ & 2411 & 4957 & 995 & 602 & 12178 & 871 & 1316 & 805 & 2698 \\
\hline
\end{tabular}

TABLE VIII. OPTIMAL COST STRUCTURE OF VALUE CHAIN IN $5^{\text {th }}$ YEAR

\begin{tabular}{|c|c|l|l|l|l|l|l|l|l|}
\hline $\begin{array}{c}\text { Value } \\
\text { Activity }\end{array}$ & $\begin{array}{c}\text { Raw Coal } \\
\text { Transpo- } \\
\text { rtation }\end{array}$ & Loading & Screening & Broken & $\begin{array}{c}\text { Heavy } \\
\text { Medium } \\
\text { Flotation }\end{array}$ & $\begin{array}{c}\text { Dehydrating } \\
\text { and } \\
\text { Classification }\end{array}$ & $\begin{array}{c}\text { Concentrat } \\
\text { e Filtering }\end{array}$ & $\begin{array}{c}\text { Coal Quality } \\
\text { Inspection }\end{array}$ & $\begin{array}{c}\text { CoalBlendi } \\
\text { ngSales } \\
\text { esService }\end{array}$ \\
\hline $\begin{array}{c}\text { optimal } \\
\text { cost } \\
\text { allocation } \\
\text { value(milli } \\
\text { on yuan) }\end{array}$ & 2295 & 4288 & 837 & 495 & 10580 & 729 & 2320 & 671 \\
\hline ratio & 5.7 & 10.7 & 2.1 & 1.2 & 26.4 & 1.8 & & \\
\hline
\end{tabular}

after-sales service coal blending sales coal quality inspection concentrate filtering dehydration and classification heavy medium flotation broken screening

loading raw coal transportation

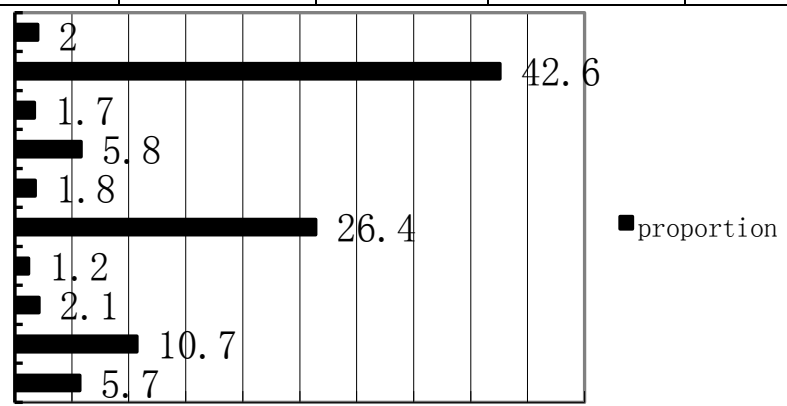

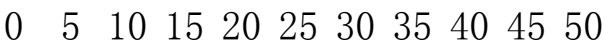

Figure 2. Proportion of each value activity

$$
\text { s.t. }\left\{\begin{array}{l}
\sum_{i=1}^{10} x_{i}^{5} \leq 40601 \\
\sum_{i=1}^{10} x_{i}^{5} \leq 40000 \\
-x_{i}^{5} \leq-x_{i}^{0}, i=1,2, \cdots, 10 \\
x_{i}^{5} \geq 0, i=1,2, \cdots, 10
\end{array}\right.
$$

Solve the FLP (by LINGO 11), the optimal cost of each value activity and the ratio of the optimal cost to total cost in the last year of a strategy planning period is shown in TABLE VIII.

\section{ANALYSIS AND SUGGESTION}

To analyze the result more conveniently and clearly, a bar chart is shown in Figure 2 on the basis of TABLE VIII. From the bar chart, the ratio of each value activity's cost to the optimal total cost could be shown clearly. Therefore, from the result, we conclude that from the point view of value chain optimization, the manager in XSMD Taiyuan coal preparation plant first needs to emphasize coal blending salesprocess during the control of the cost management. They should take coal sales as their strategy developing emphasis and ensure the variety of the type and use. The next emphasis is heavy medium
flotation,loading,Concentrate filtering and raw coal transportation, ect.

During the quantity analysis of the value chain optimization, we should ensure the analysis of the value chain structure and the collection of the allocation value of the enterprise in the early stage is reliable to make the final optimal result more practical. At the same time, it will also be benefit for the control of the company's cost and the adjustment for the strategy within the regulation period and go a step further embody the integrate profit of the enterprise value chain. In conclusion, the idea of quantity analyzing the value chain optimization could help the manager adjust the strategy of the company in time and control the cost reliably to achieve the optimization of the total cost and customer value as well as the maximum of the enterprise's profit.

\section{REFERENCES}

[1] Ming Zhang.Theoretical research and empirical analysis of value chain management[M].Northeast university of finance and economics press, 2008.(In Chinese)

[2] Jingkui Shao.Tourism industry value chain optimization and its operating mechanism[D].Henan university of science and technology,master'sthesis, 2012. (In Chinese)

[3] Michael E.porter.Competitive advantage[M].Free Press, 2004

[4] ShuliFeng.Research of China's commercial banks Competitivenessbased on the value chain optimization[D].Harbin industrial university, master's thesis, 2010. (In Chinese) 
[5] Yue Huang.Research ofenterprise internal value chain optimization model[J].Value Engineering, 2009.(In Chinese)

[6] Yongjun Wang, Qing Zhang.Analysis of the value chain extension of coal enterprises and the critical success factors under the background of globalization[J].Coal Economic Research, 2008.(In Chinese)

[7] Lunbiao Yang.Fuzzy math theory and applications (5th edition)[M].South China University of Technology Press, 2011.(In Chines)

[8] Dongping Zhao.Introduction to strategy of enterprise cost control with quantitative analysis method based on value chain optimization[J].Modern Information, 2007.(In Chinese)

[9] QiuYue.Research of Performance Evaluation System of state-owned coal enterprises[D].Heilongjiang university, master's thesis, 2007.(In Chinese) 